\title{
Streptococcus intermedius
}

National Cancer Institute

\section{Source}

National Cancer Institute. Streptococcus intermedius. NCI Thesaurus. Code C86794.

A species of facultatively anaerobic, Gram positive, cocci shaped bacteria in the phylum Firmicutes. This species is positive for arginine deaminase, esculin hydrolysis, hyaluronidase, sialidase, beta galactosidase and beta glucosidase and negative for urease and catalase. It can ferment lactose and trehalose but not arabinose, glycerol, inulin, sorbitol, raffinose or mannitol. S. intermedius is a commensal organism in humans that can be an opportunistic pathogen causing brain and liver abscesses, periodontitis and purulent infections. 